\title{
La arquitectura comercial, creación y destrucción en la ciudad actual: el caso de Oviedo (Asturias)
}

\author{
JOSÉ MARÍA RODRÍGUEZ-VIGIL REGUERA \\ Becario FPU en el Departamento de Historia del Arte y Musicología \\ Universidad de Oviedo \\ joservr@hotmail.com
}

\begin{abstract}
Resumen
La arquitectura comercial contemporánea -grandes almacenes y, sobre todo, centros comerciales- constituye desde hace varias décadas uno de los nuevos patrimonios más exitosos y enraizados en nuestras ciudades. En efecto, el paisaje urbano actual ha ido asimilando la progresiva aparición y establecimiento de una arquitectura del ocio y consumo que finalmente ha adquirido un carácter hegemónico. En este proceso de afianzamiento, más allá de sus implicaciones sociales, económicas y simbólicas, dichos espacios han sustituido -en algunos casos usurpado- el lugar ocupado por edificios singulares hoy desaparecidos. El caso de la ciudad de Oviedo (Asturias) ilustra de forma muy elocuente un proceso sincrónico según el cual el afianzamiento de nuevos patrimonios urbanos se ha hecho a costa de sacrificar una parte de la ciudad heredada.
\end{abstract}

Palabras clave: Grandes almacenes; centros comerciales; urbanismo; Oviedo; patrimonio; conservación.

\section{Commercial architecture, creation and destruction in the current city: the case of Oviedo (Asturias)}

\begin{abstract}
Contemporary commercial architecture -department stores and, especially, shopping malls- represents one of the most successfully rooted new patrimonies of our cities. Indeed, the current urban landscape has assimilated the gradual appearance and setting up of an architecture of leisure and consumption that has finally acquired a dominant position. In this process of consolidation, beyond all the social, economic and symbolic conse-
\end{abstract}


quences, these spaces have taken up -sometimes misappropriated- the place formerly occupied by singular buildings, now gone. The case of the city of Oviedo (Asturias) is very illustrative of this simultaneous process in which the consolidation of new patrimonies has meant the sacrifice of an important part of the inherited city.

Key words: Department stores, shopping malls, urbanism, Oviedo, cultural heritage, conservation.

Sumario: 1.- Introducción: la arquitectura comercial como repertorio y sus tipos contemporáneos. 2.- El centro comercial como fenómeno postmoderno: forma, estética y condición. 3.- Oviedo y sus espacios comerciales contemporáneos: creación y destrucción en la ciudad actual. 4.- Conclusiones. 5.- Apéndice gráfico. 6.- Referencias bibliográficas.

\section{Introducción: la arquitectura comercial como repertorio y sus tipos con- temporáneos.}

En todas aquellas sociedades que han desarrollado modelos económicos basados en el mercado -esto es, la prestación de bienes y servicios a cambio de dinero- (Harris, 2007: 352) es posible rastrear la presencia de espacios destinados a albergar dichas transacciones. Numerosas culturas urbanas, desde la Antigüedad hasta el epílogo postmoderno, han desarrollado construcciones que evidencian la existencia de una arquitectura comercial como repertorio tipológico. Sería imposible plantear aquí una historia de dichas formas desde ágoras a plazas porticadas, pasando por foros, mercados y bazaresque bien puede ser consultada en las compilaciones de referencia (Pevsner, 1979; Coleman, 2006). Es en época contemporánea cuando se gestan, al calor del emergente sistema económico capitalista, tres singulares modelos arquitectónicos que han participado de forma muy considerable en la conformación del paisaje urbano europeo, americano y finalmente global.

Hablamos de las galerías (también arcades o pasajes), los grandes almacenes y los centros comerciales. El primer caso surge a finales del s. XVIII en París con las galerías del Palais Royal (Amendola, 2000: 189) y adquiere notoriedad a lo largo del s. XIX en todas aquellas ciudades en expansión -ensanches- necesitadas de espacios de ocio y exposición para la emergente burguesía. Son célebres los magníficos ejemplos de Bruselas, Nápoles o Milán (Coleman, 2006:31- 
33), y más modestos los documentados en ciudades españolas como Madrid, Barcelona, Valladolid u Oviedo (Navascués y Quesada, 1992: 128).

Los grandes almacenes representan un paso más en la evolución de la arquitectura comercial contemporánea. Su principal característica y diferencia respecto a los anteriores pasajes reside en el hecho de que toda su oferta comercial se encuentra concentrada bajo una sola empresa o gestión, en un único espacio en el que las emergentes clases medias urbanas cobran protagonismo como sujetos adquiridores. Presentan gran desarrollo en superficie y altura, organizados en varias plantas que no pocas veces ocupan enteramente un edificio exento. Suelen contar con una fachada privilegiada dotada de importantes escaparates, y recurren a la planta libre para distribuir sin limitaciones las diferentes mercancías, así como a artilugios mecánicos tales como rampas y escaleras automáticas o ascensores para facilitar el desplazamiento de visitantes y objetos. El primer ejemplo lo constituirían los almacenes Bon Marché de París, fundados en 1852 y reformados en varias ocasiones (Pevsner, 1979: 320-321; Miller, 1981). Esta exitosa propuesta comercial rápidamente trascendió el ámbito parisino extendiéndose por toda Europa y finalmente dando el salto al otro lado del Atlántico, algo que explica Pevsner al afirmar que "los años 1870-1910 vieron en Norteamérica un espectacular crecimiento de los negocios de los grandes almacenes" (Pevsner, 1979: 326). En España, como señala Pilar Toboso, es difícil hablar de negocios con características homologables a las de los grandes almacenes extranjeros antes del período franquista, siendo el primer Galerías Preciados de Madrid, inaugurado en 1943, pionero en su clase (Toboso, 2002: 27-50).

El centro comercial constituye el tercer y último de los tipos arquitectónicos nacidos en época contemporánea, considerado por Giando-menico Amendola la nueva gran presencia de nuestras ciudades (Amendola, 2000: 251).

Las diferencias respecto a sus precedentes son palpables: frente a la usual pequeñez de la galería decimonónica y el carácter concentrado y monolítico del gran almacén, el centro comercial presenta estructura múltiple y pluralidad funcional, lo que se traduce en una distribución arquitectónica más compleja en la que coexiste una variada suma de unidades de consumo que superan la noción de tienda e incluyen establecimientos ligados al ocio tales como cines, restaurantes, hoteles, casinos, locales deportivos, parques de atracciones, etc. Se 
suele admitir que el Southdale Center en Edina -Minnesota, EEUU- inaugurado en 1956, constituye el primer ejemplo claro de centro comercial (Escudero, 2008: 105): diseñado por Victor Gruen, "padre" del mall norteamericano (Harwick, 2004), presenta buena parte de los rasgos que se atribuyen a los centros comerciales aún en la actualidad ${ }^{1}$. Desde la década de 1960 el centro comercial experimenta un crecimiento exponencial que, tal como señala Luis A. Escudero, es exportado desde Norteamérica primero a Europa e inmediatamente después al resto del planeta. (Escudero, 2008: 121-151). En España se considera a Baricentro, inaugurado en 1980 y situado en las inmediaciones de Barcelona, el primer centro comercial suburbano (Ibíd.: 153-154).

\section{El centro comercial como fenómeno postmoderno: forma, estética y con- dición.}

Durante la Postmodernidad acontece la última vuelta de tuerca de un sistema capitalista que consigue dominar el plano simbólico del consumo para consolidarlo como rito de posicionamiento distintivo y afianzamiento identitario no ya de una minoría, sino de una masa social más consumidora que productora (Bauman, 2001: 54). En una sociedad en que el consumo supera la simple necesidad -adquirir para cubrir funciones básicas- y se convierte en acto de representación, el centro comercial surge como escenario idóneo: su importante posición dentro de la sociedad urbana actual ha llevado a identificarlo como "catedral" o "paisaje del consumo" (Kowinski, 1985: 218; Ritzer, 2005: 142-172). Desde un punto de vista formal, la arquitectura comercial maneja principios dirigidos a crear una experiencia adquisitiva cómoda.

Tiende al hermetismo, aislando al comprador en un universo deslocalizado, idílicamente protegido y detenido en el tiempo, y emplea soluciones estructurales como pirámides, bóvedas de cañón o cúpulas translúcidas, a un tiempo funcionales -iluminan de forma natural el espacio- y simbólicas -

\footnotetext{
${ }^{1}$ Por ejemplo: diseño de líneas rectas, estética "de caja" asociada a su hermetismo, contraste entre su sencillez exterior y un acondicionamiento interior en el que no faltan ni los sistemas de climatización en pos del confort ni la simulación de un entorno urbano mediante la incorporación de mobiliario ad hoc.
} 
prestigio de determinado lenguaje-. La direccionalidad es otro aspecto que se manifiesta en la organización de grandes vías principales, recorridos calculadamente instintivos y una colocación estratégica de escaleras, rampas automáticas, ascensores o puertas. Los rasgos anteriormente descritos se asocian además a una estética comercial particular, típicamente postmoderna en su gusto por el pastiche, el simulacro y lo que Jameson denomina "populismo estético" (Jameson, 1991: 11-12). Es habitual la recreación de entornos urbanos, evocando no sólo calles, sino épocas remotas o culturas exóticas. La tematización como solución estética hace del centro comercial el escenario donde desplegar diversas referencias, en ocasiones teñidas de un mínimo sentimentalismo -alusiones a lo vernáculo, a la identidad local- pero muchas veces manejadas como estereotipos destinados a dulcificar la experiencia comercial y crear una brecha profunda entre la realidad urbana exterior y la amable hiperrealidad interior. También merecen mención cierta tendencia al gigantismo, el estímulo y la espectacularidad más típicamente neobarrocos y no pocas veces descaradamente kitsch.

El debate crítico, más allá de las consideraciones formales y estéticas, se plantea en torno a la condición del centro comercial como producto (in)humano y (anti)social. Se ha señalado insistentemente cómo dichos espacios reproducen los más siniestros esquemas del modelo panóptico, fomentando el encierro del ciudadano en una alienante cárcel donde todo está científicamente calculado en torno al consumo y cualquier acción alternativa resulta indeseable (Alonso, 2006: 109-110; Amendola, 2000: 220). En una línea similar cabe recordar la idea de no-lugar acuñada por Marc Augé, quien habla al respecto de "un espacio que no puede definirse ni como espacio de identidad, ni como relacional ni como histórico" (Augé, 2005: 83), diseñado para acoger a un ciudadano-pasajero considerado únicamente en términos burocráticos o económicos. Otros autores han elaborado lecturas más permisivas, identificando sus posibilidades sociales: a este respecto, José E. Finol, reconociendo el nuevo papel del mall como plaza pública ${ }^{2}$, afirma que "este espacio es un lugar de encuentro, de socialización y, sólo marginalmente, un lugar de

\footnotetext{
${ }^{2}$ Si se nos permite la matización, pública en tanto que frecuentada por el pueblo, pues su titularidad como entidad suele ser por definición privada.
} 
consumo al que se va a comprar" (Finol, 2004: 54). Igualmente destacan las investigaciones en torno a la dinámica establecida entre los centros comerciales y aquellos grupos humanos que los visitan, generando vínculos emocionales con el mismo, concepciones identitarias y atribuciones simbólicas ligadas al hecho de frecuentarlo: Inés Cornejo sintetiza esta cuestión afirmando que "la constante asistencia de hombres o mujeres, jóvenes o adultos transforman el centro comercial de lugar anónimo a territorio conquistado, apropiado, íntimo" (Cornejo, 2006: 27).

\section{Oviedo y sus espacios comerciales contemporáneos: creación y destruc- ción en la ciudad actual.}

Más allá de las apreciaciones y reflexiones generales planteadas desde enfoques sociológicos, geoeconómicos o antropológicos, los espacios de consumo más recientes aún están en espera de ser estudiados en profundidad desde una perspectiva histórico-artística, cuestión apenas tratada para el ámbito español, por otra parte tan permeable a dicha arquitectura. Estas nuevas "catedrales" merecen ser analizadas desde una óptica que valore sus características funcionales, estilísticas y estéticas, su decisivo protagonismo en la articulación viaria y zonal de las ciudades españolas y sus periferias y su influyente papel en relación a la gestión del suelo urbano y la conservación del patrimonio precedente. Consideramos que el caso de Oviedo, capital del Principado de Asturias, resulta particularmente ilustrativo respecto a los puntos previamente señalados. A juicio de Aladino Fernández, dicha región se encontraba hace ya unos años "al borde de la saturación" en términos de arquitectura comercial (Fernández, 2003:341), con dieciocho establecimientos hoy activos si contamos únicamente grandes almacenes y centros comerciales- en un territorio poblado por poco más de un millón de habitantes. Oviedo, ciudad con funciones tradicionalmente administrativas y terciarias, ha presenciado en las últimas décadas la construcción dentro de su área de unos grandes almacenes -Galerías Preciados, hoy El Corte Inglés- y cuatro centros comerciales -Salesas, Centro Cívico Comercial, Los Prados y Modoo- que hoy ocupan una notable posición dentro del paisaje urbano, definiendo su apariencia y articulando su distribución y funcionamiento (Rodríguez-Vigil, 2011). Con la excepción del Centro Cívico Comercial, construido sobre un gran solar vacío, estas edificaciones se han ido imponiendo paulatinamente, ocupando el lugar 
en que anteriormente se levantaban diversos ejemplos de patrimonio residencial, religioso, industrial y deportivo.

Como demostraremos a continuación, desde hace años en la ciudad de Oviedo viene produciéndose, en paralelo a la puesta en marcha de nuevos espacios de consumo, una desafortunada disolución de la ciudad heredada, eliminándose vestigios susceptibles de haber sido respetados aprovechando su desprotección o la débil conciencia ciudadana de la época, y escudándose en cierto ideal de progreso. La Ley 1/2001, de 6 de marzo, del Patrimonio Cultural del Principado de Asturias establece desde hace más de una década un contexto normativo: en los capítulos I y II del Título II de la misma quedan bien especificados aspectos tales como los grados de protección, los supuestos para la declaración de ruina, los condicionantes para la concesión de licencias urbanísticas y otras tantas cuestiones vinculadas al tema que tratamos. Lamentablemente, este marco se perfiló tardíamente, tras décadas de operaciones poco acertadas. Comenzaremos analizando la obra de Galerías Preciados (apertura en 1975), a nuestro juicio primera gran muestra de arquitectura comercial del Oviedo actual. Aunque en la capital asturiana ya existían algunos establecimientos y almacenes de cierta importancia (Al Pelayo, Botas), la llegada del emporio de Pepín Fernández supuso la implantación de un espacio comercial de dimensiones y alcance hasta la fecha desconocidos en la ciudad. El lugar elegido para la construcción de Galerías Preciados fue un solar situado en pleno corazón del barrio de Uría, ensanche decimonónico y núcleo del sector servicios (Pérez, 1977), en la esquina formada por las calles Uría y Gil de Jaz. Dicho solar venía siendo ocupado, desde hacía más de cinco décadas, por un gran chalet propiedad de la influyente familia Tartiere. El palacete, considerado por Sergio Tomé una obra ligada a "la difusión del estilo 'Renacimiento español"' (Tomé, 1988:182), fue trazado por el arquitecto Manuel Bobes y Díaz, quien en nombre de José Tartiere presentó al Ayuntamiento planos para la construcción del mismo en enero de $1916^{3}$. De alzado clasicista, rematado por un potente torreón prismático apilastrado, con balcones y cornisas de gran desarrollo, este edificio -documentable en fotografías de la dé-

${ }^{3}$ Archivo Municipal de Oviedo (AMO), cuerpo de estante 1, estante 1, legajo 69, documento 10. 
cada de 19204- formaba parte de un barrio que originalmente albergó numerosas villas unifamiliares, extinguidas a lo largo del s. XX a manos de la piqueta y sucesivas iniciativas urbanísticas (Morales, 1981). El chalet Tartiere no tuvo mejor fortuna: en diciembre de 1972 el periódico local La Nueva Espa$\tilde{n} a$ anunciaba la venta de la finca de Tartiere, "con destino, lógicamente, a la construcción de un bloque de viviendas y galerías comerciales"5. En marzo de 1973 el propio Pepín Fernández confirmaba al mismo diario la próxima instalación de una sucursal de Galerías Preciados en Oviedo; la noticia, evidenciando la inminente destrucción del citado palacete -que tendría lugar en el mes de mayo-, señalaba al respecto: "sus almacenes en la capital del Principado se ubicarán en el gran edificio a construir en el solar que deja, por derribo, el chalet Tartiere, en la esquina Uría-Gil de Jaz, importante y céntrico enclave urbano (...) Galerías Preciados S.A. (...) ha adquirido dicho solar por una cifra respetable que supera los 200 millones de pesetas"6. Unos meses después, en julio de 1973, se entregaba el anteproyecto de un edificio destinado a gran almacén, diseñado por Javier Feduchi Benlliure y Francisco Bassó Birulés (autores de diseños para Galerías Preciados en Madrid-Goya y Zaragoza con características similares) ${ }^{7}$. El posterior proyecto, idéntico en lo sustancial, fue presentado en marzo de 1974, siéndole concedida licencia de construcción el 18 de abril del mismo año ${ }^{8}$. El nuevo recinto comercial fue inaugurado con gran boato el 15 de mayo de $1975^{\circ}$. Su arquitectura, que apenas ha cambiado hasta nuestros días, se caracteriza por la depuración de sus fachadas de chapa esmaltada color crema, solamente perforadas por vanos en los escaparates a nivel de suelo y en la esquina ocupada por la escalera, y rematadas en planta baja y azotea por potentes marquesinas voladas de aluminio plegado.

En octubre de 1982 abrió sus puertas el Centro Comercial Salesas, el primero en su tipo de la ciudad y popular espacio de tránsito y recreo hasta la actualidad. Su nombre hace referencia directa al desaparecido monasterio homónimo, tam-

${ }^{4} \mathrm{AMO}$, colección fotográfica.

${ }^{5}$ La Nueva España (LNE), 08-12-1972, pág. 10.

${ }^{6}$ LNE, 31-03-1973, pág. 10.

${ }^{7}$ AMO, Expediente 2401/73, pág. 27 y Memoria del anteproyecto.

8 AMO, Expediente 876/74, Memoria del proyecto y pág. 14.

${ }^{9}$ LNE, 16-05-1975, pág. 10. 
bién conocido como "de la Visitación", completamente derribado a excepción de su iglesia, que fue conservada, para posibilitar la edificación del citado complejo residencial-comercial. Situado en una extensa finca delimitada por las calles Nueve de Mayo y General Elorza, en un barrio intermedio próximo al eje de Uría, el monasterio de Salesas constituía, a juicio de Morales Saro, "la obra más interesante de Federico Aparici en Oviedo" (Ibíd.: 130-131): el que fuera arquitecto de la basílica de Covadonga ideó para la comunidad de monjas de la Visitación un edificio de formas recias, organizado en torno a un patio claustral de planta cuadrada y estética severa, en obras durante la década de 1880 y habitado desde 1885. La iglesia adyacente, consagrada en 1903 y trazada en estilo neogótico, pudo ser igualmente planteada por Aparici, si bien Juan Miguel de la Guardia y Julio Galán le dieron la forma que hoy presenta (Ibíd.: 130). En el año 1973 las monjas deciden trasladarse, poniendo en venta el solar y el monasterio, adquiridos por la empresa Balsera (Diego, 2009: 175). Dicha compañía propuso al Ayuntamiento un ambicioso anteproyecto urbanístico ideado por los arquitectos Alejandro y Alfredo Miranda que aprovechando el considerable desnivel del terreno planteaba la construcción de una estación de autobuses, galerías comerciales, hotel, bloques de apartamentos y zonas verdes, todo ello articulado a modo de gran patio de manzana escalonado ${ }^{10}$. Esta iniciativa no prosperó y los terrenos fueron traspasados a otra empresa, la inmobiliaria Promociones Laureano, que replanteó el diseño previo con un nuevo proyecto de centro comercial y conjunto residencial ideado por Juan F. Álvarez Quirós que sí se llevó a cabo y se corresponde con los edificios hoy existentes ${ }^{11}$.

Aunque la prensa local informaba ya en agosto de 1976 del inicio de las obras previas de demolición y excavación en la finca del monasterio ${ }^{12}$, el arquitecto Álvarez Quirós no solicitó licencia para su destrucción -adjuntando una memoria de derribo- hasta el mes de diciembre, siéndole concedida en enero de 197713. En dicha memoria se afirmaba, acerca del conjunto existente, que "por la situación de los edificios, como por su estado, respecto a las redes de

\footnotetext{
${ }^{10}$ AMO, Expediente 1306/74.

${ }^{11}$ AMO, Expedientes 2542/76, 3844/76, 3170/77, 2222/78 y 1048/79.

12 LNE, 22-08-1976, pág. 7.

${ }^{13}$ AMO, Expediente 3908/76, Memoria y pág. 9.
} 
servicios, se considera que su desaparición no afectará a la infraestructura urbanística de su entorno", valoración que cuestionamos, pues si bien es cierto que el derribo en sí no generó daños inmediatos a las construcciones circundantes, la eliminación del monasterio sí implicó una radical transformación, no necesariamente negativa, pero desde luego a tener en cuenta: la obra del Centro Comercial Salesas, articulado como un conjunto cubierto de tiendas en torno a plataformas aterrazadas, dotado de ascensores, escaleras automáticas y rampas, no solo supuso la apertura de un gran espacio transitable tendido entre el centro de la ciudad y sus barrios inmediatos, sino la inserción de grandes bloques de apartamentos, de varias plantas y forma maciza, con una alta densidad de ocupantes, con considerable impacto visual.

La obra del Centro Cívico Comercial, tercer gran espacio de consumo del Oviedo actual -cuya construcción se remonta a un primer proyecto de 1979 abortado y sustituido una década después por un segundo plan inaugurado en 199314- no implicó la desaparición de ningún conjunto arquitectónico singular previo, constituyendo una excepción en nuestro análisis que justifica su supresión del presente relato. No podemos decir lo mismo del Centro Comercial Los Prados: situado en una zona excéntrica de la ciudad, en origen asociada a una extracción social humilde -presencia de diversas colonias obreras- y tradicionalmente segregada por diversos factores -un Hospital Psiquiátrico, el Matadero Municipal, un "cinturón de hierro" de raíles de ferrocarril- la apertura de dicho centro comercial desencadenó, unida a iniciativas paralelas -operación Cinturón Verde, construcción del nuevo Hospital Universitario Central de Asturias en los terrenos del Psiquiátrico- una radical transformación del territorio ligada a un claro intento de rezonificación. Los Prados ocupa la parcela donde durante décadas permanecieron en pie las estructuras del Matadero Municipal, conjunto proyectado en 1925 por el arquitecto Luis de Sala por encargo del Ayuntamiento de Oviedo tras ganar un concurso previamente celebrado ${ }^{15}$. Dicho proyecto -en cuya memoria el arquitecto dice haber realizado "un largo viaje de estudio para recoger datos de los mejores mataderos de la Europa Central" citando el ejemplo de Budapest- fue tramitado y ejecutado entre 1926 y 1932, año en que las tareas

${ }^{14}$ AMO, Expedientes 2278/79 y 1202-900089. Noticia sobre su apertura en LNE, 22-07-1993, p. 4.

${ }_{15} \mathrm{AMO}$, cuerpo de estante 1 , estante 1 , legajo 156, documento 5. 
de construcción y equipamiento concluyeron definitivamente, tras sucesivas fases $^{16}$. Los arquitectos José Avelino Díaz, Francisco Casariego y Enrique Rodríguez Bustelo, así como el ingeniero Sánchez del Río aparecen mencionados en la documentación, vinculados circunstancialmente al proceso en calidad de arquitectos municipales o inspectores de las obras e instalaciones, presentes también estos tres últimos técnicos en las entregas provisional -23 de abril de 1932- y definitiva -13 de enero de 1933- del conjunto ${ }^{17}$.

Clausurado en enero de 1990 tras un informe negativo de la Consejería de Sanidad, el Matadero experimentó un veloz deterioro derivado de la interrupción de sus actividades, convertido en almacén municipal e improvisado albergue de toxicómanos: la parcela despertó entonces el interés de las administraciones autonómica y municipal, que plantearon respectivamente la construcción en dichos terrenos de un auditorio y un palacio de congresos ${ }^{18}$.

Sin que nada se hubiera aclarado acerca de los futuros usos de la finca una vez desescombrada, se inició la demolición parcial del conjunto industrial del Matadero mediante una resolución de la Alcaldía ovetense a fecha 20 de agosto de 1992 ${ }^{19}$ : dicha demolición, puesta en práctica cuatro días después, respetó el edificio de oficinas del macelo y las naves del mercado de ganado ${ }^{20}$.

Estos últimos testimonios serían en cualquier caso destruidos cuando, una vez abandonados los proyectos inicialmente planteados para la zona, en 1997 se decidió adjudicar la parcela a Continente/Carrefour para la construcción de un

\footnotetext{
${ }^{16} \mathrm{AMO}$, cuerpo de estante 1, estante 1, legajos 157 y 158. Luis de Sala ideó un amplio complejo con las preceptivas naves para el degüello de ganado vacuno, porcino, lanar y avícola, igualmente dotado de establos, mondonguería, pabellón con cámaras frigoríficas -entonces una importante novedad- y una nave de exposición para ganado vacuno destinada a acoger la celebración de mercados, así como un edificio central en el que dispuso la bolsa de contratación, administración, viviendas y restaurante.

${ }_{17} \mathrm{AMO}$, cuerpo de estante 1, estante 1, legajo 158, documentos 2, 3, 6, 14 y 16. Véanse también las noticias "Han sido totalmente terminadas las obras del nuevo Matadero" y "El próximo sábado se hará cargo el Ayuntamiento del nuevo Matadero" en El Carbayón, 11-02-1932, pág. 2 y 16-04-1932, pág. 4, y "La recepción del nuevo Matadero" en El Noroeste, 24-04-1932, pág. 2. ${ }^{18}$ LNE, 25-08-1992, pág. 4.

${ }_{19} \mathrm{AMO}$, Expediente CC92/400, con asunto "Obras derribo naves matadero municipal".

${ }^{20}$ LNE, 25-08-1992, pág. 4.
} 
gran centro comercial diseñado por Emilio Llano que fue abierto al público en mayo del año $2002^{21}$. La nueva obra, de formas estereotipadas en hormigón visto y chapa, desornamentada y sin elementos singulares más allá de una simple cubierta curvada y una torre-linterna a modo de hito visual y nexo entre los dos grandes bloques que integran el centro comercial, tiene interés fundamentalmente como elemento propiciatorio dentro de la forzada reconversión de la zona en un paradójico "centro periférico" -la publicidad inmobiliaria del momento fue más que elocuente al respecto ${ }^{22}$ - donde en la última década han emergido enormes bloques residenciales, algunos de considerable lujo, que evidencian un impetuoso afán urbanizador más especulativo que social ligado según Miguel Moro a evidentes procesos de gentrificación (Moro, 2007: 109 y 116-117).

Hasta la fecha Modoo (inicialmente llamado Espacio Buenavista) representa el más reciente centro comercial de la ciudad. Está integrado prácticamente oculto- en la ciclópea y polémica estructura del Palacio de Congresos de Oviedo, creación de Santiago Calatrava ubicada en el lugar restante tras la demolición del antiguo Estadio Carlos Tartiere, en el barrio de Buenavista. La edificación de este conjunto -que aparte del palacio de congresos y el centro comercial, incluye oficinas del Principado y un hotel- es el resultado de un largo e intrincado proceso de entrega y explotación simultánea de dos grandes fincas municipales -la del citado estadio de Buenavista y la de los terrenos de la también desaparecida Estación de ferrocarril del Vasco, en pleno corazón de Oviedo- a la sociedad Jovellanos XXI, con el fin de construir en ambas diversas arquitecturas ideadas por Santiago Calatrava de las cuales solo se ejecutó el proyecto aquí tratado (Morales, 2009). El desaparecido Estadio Carlos Tartiere, inicialmente conocido como Stadium de Buenavista, fue proyectado en 1930 por los ya mencionados arquitectos Casariego y Rodrí-

\footnotetext{
${ }^{21}$ Algunos funcionarios residentes en el Matadero siguieron ocupando sus viviendas hasta que en septiembre de 1997, coincidiendo con el inmediato arranque de las obras del nuevo hipermercado, el Ayuntamiento se vio obligado a desahuciarles. LNE, 03-09-1997. Tramitación de las obras en AMO, Expediente 1202-980020. Sobre la inauguración del centro, ver LNE, 23-052002, págs. 28-29.

22 Por ejemplo: "Residencial Rubín $2^{\text {a }}$ Fase (...) es el momento de invertir en la zona más pujante de Oviedo", en LNE, 23-05-2002, pág. 33 y también "Los Álamos del Villar le ofrece la oportunidad de vivir en el nuevo centro de Oviedo", en LNE, 01-06-2003, pág. 9.
} 
guez Bustelo y el ingeniero Sánchez del Río, quien ideó una vanguardista tribuna con visera volada de hormigón situada en el margen norte del campo ${ }^{23}$. Inaugurado en abril de 1932, el edificio sufrió daños durante la Guerra Civil, teniendo que ser intervenido. Tal como se explica en el informe de la memoria del proyecto de demolición redactado en 2002, durante las décadas siguientes se sucedieron distintas reformas y ampliaciones, siendo la más importante la completa remodelación del mismo para adaptarlo como sede regional del Mundial de Fútbol de 1982: fue entonces cuando, según proyecto del arquitecto Florencio Uribe, se reconstruyeron y acondicionaron enteramente las tribunas preexistentes, interviniéndose igualmente sobre la estructura de Sánchez del Río, adquiriendo el estadio su forma definitiva ${ }^{24}$.

Dos décadas después, contando la ciudad con un Nuevo Estadio Carlos Tartiere -inaugurado en el año 2000, obra de Emilio Llano, autor del Centro Comercial Los Prados-, y con el ambicioso objetivo en el horizonte de dar un uso diferente a la finca de Buenavista, la Alcaldía dio vía libre al derribo del viejo estadio en octubre de 2002, iniciándose su destrucción el 27 de enero de $2003^{25}$. Una vez desaparecido, se desencadenó el proceso de especulación con la parcela restante ya mencionado, hasta que en 2005 se iniciaron los trabajos de construcción del Palacio de Congresos, culminados en 2011 tras numerosos avatares ${ }^{26}$; a medida que las dilatadas obras avanzaban, se produjo una progresiva ocupación de sus dependencias, incluyendo el centro comercial cuya memoria firmaron Pablo Reinares y María del Val Menéndez, de TAU Arquitectos $^{27}$ - abierto en marzo de 2008.

23 Puede verse el proyecto primitivo en AMO, cuerpo de estante 1, estante 1, legajo 184, doc. 2.

${ }^{24}$ AMO, Expediente 1214-02-34, Memoria Proyecto de derribo y demolición del antiguo estadio "Carlos Tartiere" de Oviedo. La reinauguración del estadio reformado tuvo lugar el 29 de abril de 1982 con un partido que enfrentó al Real Oviedo con la selección de Chile. Ver LNE, 30-041982, págs. 21-23.

${ }^{25}$ Aprobación del proyecto de demolición el 8 de octubre de 2002 en AMO, Expediente 121402-34, p. 210. Noticia sobre el inicio de la demolición en $L N E, 28-01-2003$, portada y págs. 3 y 4. ${ }^{26}$ Un resumen gráfico del proceso de construcción en LNE, 09-05-2011, págs. 4-5.

${ }^{27}$ La posible dedicación de los pisos inferiores del Palacio de Congresos para usos comerciales fue prevista por Calatrava, si bien el trazado del centro comercial propiamente dicho se debió a los ar- 
Modoo constituye un ejemplo bastante genérico de espacio comercial: articulado en tres niveles en torno a un patio central longitudinal, con pasillos perimetrales y plazas secundarias -con un plano de direccionalidad difusa un tanto incómodo- su interior estandarizado contrasta con el despliegue visual exterior del Palacio de Congresos del que forma parte. En efecto, es el espectacular "envoltorio" del conjunto, con sus brazos volados y su potente estructura de costillas a modo de casco con visera -por cierto, de fallidas pretensiones cinéticas, concebida para ejecutar cierto movimiento retráctil pero permanentemente detenida por problemas técnicos- el elemento que atrae toda la atención, desgraciadamente para suscitar juicios más bien negativos: sus exageradas dimensiones contrastan dramáticamente con el entorno inmediato donde más que insertarse, se impone unilateralmente compitiendo con las vecinas torres de viviendas, colegio y parroquia casi como un objeto extraño emergido de repente (Ibíd.: pág. 161). Su elevación, unida a la ya de por si disposición en una zona alta de la ciudad, también ha tenido consecuencias para la percepción del paisaje urbano en la distancia: desde las afueras monte Naranco y zona de San Esteban de las Cruces- su radical irrupción en el skyline de la capital resulta evidente.

\section{Conclusiones}

En las páginas previas hemos trazado un relato general sobre la historia de la arquitectura comercial contemporánea -contemplando sus facetas tipológicas, estéticas y socioculturales- para profundizar después en un estudio del desarrollo de este repertorio en un contexto local como es el de la ciudad de Oviedo. Hemos podido constatar cómo la implantación de este nuevo patrimonio lúdico-comercial emergente en la capital asturiana coincide repetidamente con la sistemática aniquilación de monumentos singulares de la ciudad heredada, a los cuales se ha negado la posibilidad de perpetuarse como material histórico para las generaciones futuras, a pesar de su argumentable interés. Una vez probado este proceso dialéctico de creación y destrucción de patrimonios -y

quitectos Pablo Reinares y María del Val Menéndez. Consúltese Lavozdeasturias.es, 30 de agosto de 2006, http://archivo.lavozdeasturias.es/html/291875.html.

Ver también http://tauarquitectos.com/main.htm. [enlaces consultados a fecha 07-11-2012; 10:30] 
por extensión, de identidades- en la ciudad de Oviedo, resulta necesario matizar nuestro análisis: sería desacertado deducir que la nueva arquitectura comercial ha sido siempre la causa directa y exclusiva de estos procesos de borrado de las huellas patrimoniales precedentes. Sin embargo, sí podemos llamar la atención sobre un hecho evidente: bien de manera premeditada y explícita o como resultado último y "casual" de operaciones urbanísticas e inmobiliarias tan ambiciosas como sospechosas, esta arquitectura comercial termina imponiéndose como una suerte de respuesta comodín ante cualquier incógnita planteada con la dinamización de suelos liberados o disponibles.

No es nuestra intención condenar la creación de nuevos espacios de consumo en la ciudad -dignos hijos de su tiempo, en ocasiones incluso resultan interesantes por su audaz concepción urbanística (Salesas) o vinculación a un "tipo" identificable (Galerías Preciados y su estética característica)- pero sí mostrar disconformidad respecto a su reiterativa presencia, casi monológica, y sobre todo, lamentar la manera en que se han asentado en el tejido urbano, suprimiendo los patrimonios precedentes. Las destrucciones "colaterales" de que Oviedo ha sido víctima y testigo, más allá de la desaparición de los edificios citados, aluden a planos menos tangibles, relacionados bien con la estética del entorno urbano (agresiva imposición del Palacio de Congresos en Buenavista e incidencia en la percepción general de la ciudad), bien con su equilibrio demográfico, político e identitario (rezonificación y reinvención acelerada e interesada del área en torno al Centro Comercial Los Prados).

Lejos de haberse detenido, la utilización del suelo municipal para la edificación de grandes espacios de consumo parece seguir activa ${ }^{28}$, lo que nos habla de una escasa por no decir nula conciencia por parte de los poderes electos respecto a la necesidad de una gestión más equilibrada, respetuosa, sostenible y en definitiva social de un espacio público constantemente agredido y privatizado.

\section{Apéndice gráfico}

\footnotetext{
${ }^{28}$ Proyecto actualmente en obras en la parcela Jovellanos 2 (El Vasco), con posibles usos comerciales. Ver LNE, 03-01-2011, pág. 3.
} 


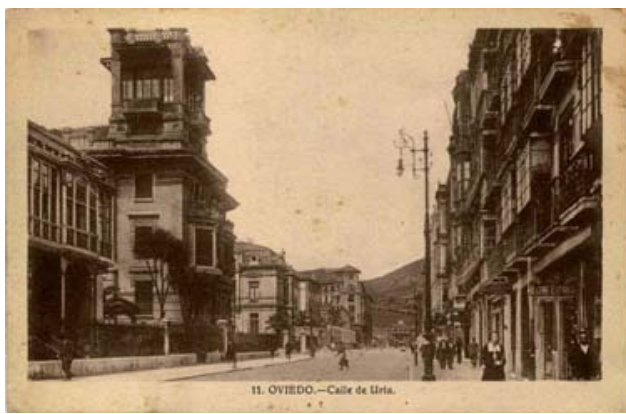

Fig. 1. La calle Uría en la década de 1920, a la izquierda el Chalet Tartiere. Fuente: AMO.

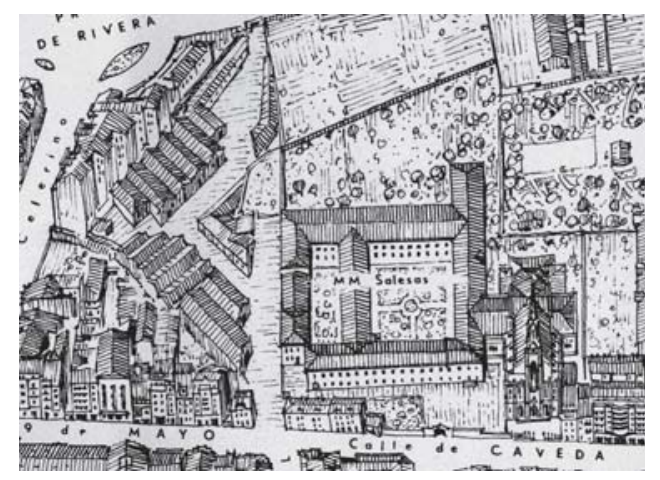

Fig. 3. La iglesia, monasterio y finca de las Salesas de Oviedo en el plano de Luis Fresno de 1965. Fuente: AMO

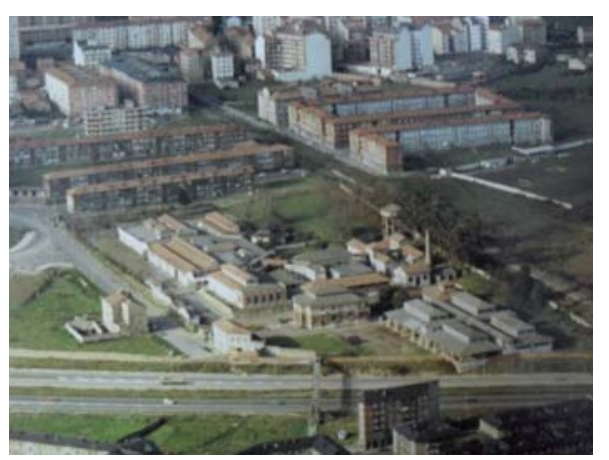

Fig. 5. Detalle del conjunto industrial del Matadero Municipal a mediados de la década de 1980. Fuente: AMO, reportaje aéreo 1984-1985.

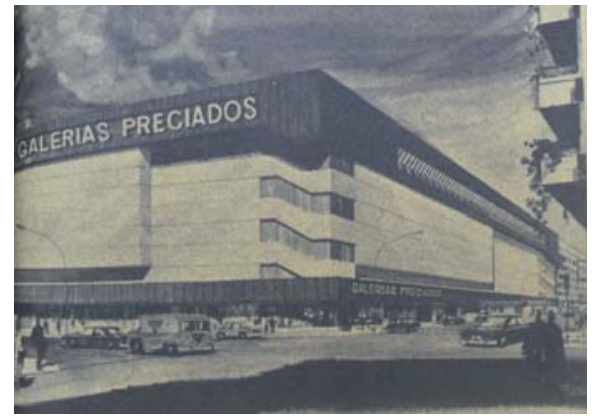

Fig. 2. Diseño de Feduchi y Bassó para el anteproyecto de Galerías Preciados en Oviedo.

Fuente: AMO, Expediente 2401/73.

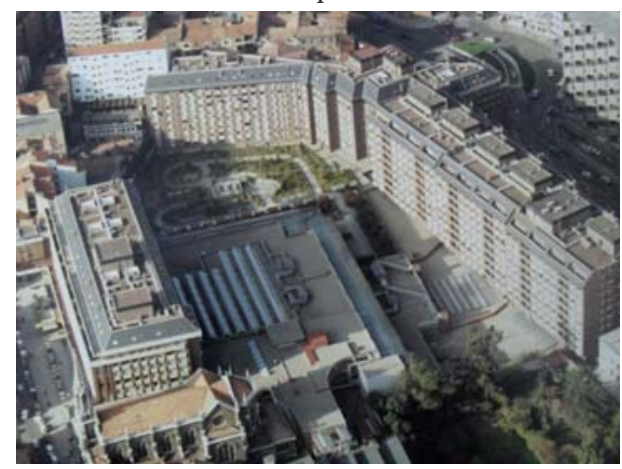

Fig. 4. El Centro Comercial Salesas y su conjunto residencial, en el ángulo inferior izquierdo se observa la iglesia conservada. Fuente: AMO, reportaje aéreo 1984-1985.

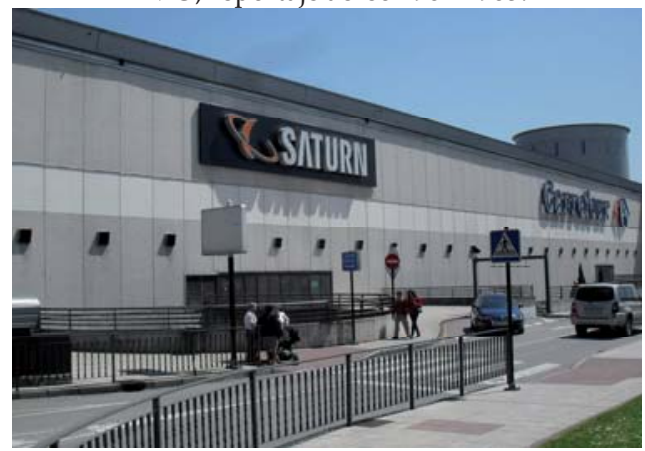

Fig. 6. El Centro Comercial Los Prados en la actualidad, detalle del hipermercado, al fondo la torre. Fuente: Fotografía del autor.

Arte y Ciudad - Revista de Investigación 2013 (Junio) $n^{\circ} 3$ (I) Extraordinario 


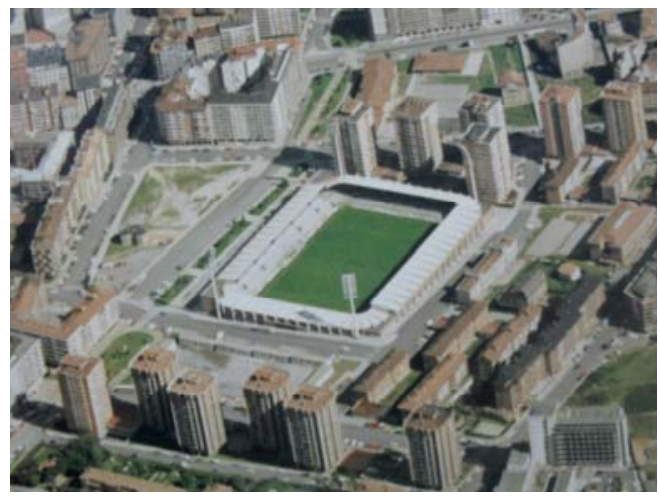

Fig. 7. Detalle de vista aérea del barrio de Buenavista, en el centro aparece el desaparecido Antiguo Estadio Carlos Tartiere. Fuente: AMO, reportaje aéreo 1984-1985.

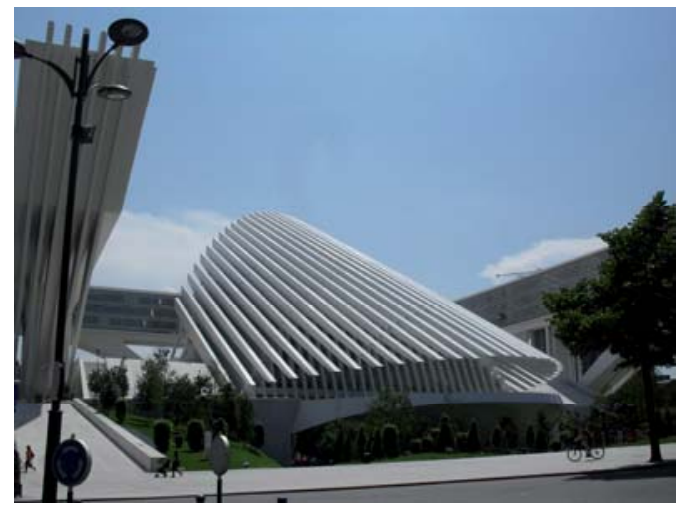

Fig. 8. El Palacio de Congresos de Oviedo en la actualidad, el centro comercial ocupa el espacio inferior. Fuente: Fotografía del autor.

\section{Bibliografía}

ALONSO, L. E. (2006): La era del consumo, Siglo XXI de España Editores, Madrid. AMENDOLA, G. (2000): La ciudad postmoderna, Celeste Ediciones, Madrid.

AUGÉ, M. (2005): Los no lugares, espacios del anonimato. Una antropología de la sobremodernidad, Gedisa, Barcelona.

BAUMAN, Z. (2001): La posmodernidad y sus descontentos, Ediciones Akal, Madrid.

COLEMAN, P. (2006): Shopping environments: evolution, planning and design, Architectural Press, Oxford.

CORNEJO, I. (2006): "El centro comercial desde la comunicación y la cultura. Un modelo analítico para su estudio". Convergencia: Revista de ciencias sociales, $\mathrm{n}^{\mathrm{o}}$ 40, enero-abril, Universidad Autónoma del Estado de México, págs. 13-37.

DiEGO, J. L. (2009): Historia de la comunidad de monjas de la orden de la Visitación de Santa María de la Ciudad de Oviedo, Madrid.

ESCUDERO, L. A. (2008): Los centros comerciales: espacios postmodernos de ocio y consumo, Ediciones de la Universidad de Castilla-La Mancha, Cuenca.

FERNÁNDEZ, A. (2003): "Hipermercados y centros comerciales en Asturias", Ería, 62, Universidad de Oviedo, págs. 341-349.

FINOL, J. E. (2004): "Globalización, espacio y ritualización: de la plaza pública al Mall". En Muro, Miguel Ángel (coord.). Arte y nuevas tecnologías: X Congreso 
de la Asociación Española de Semiótica, Fundación San Miguel de la Cogolla Universidad de la Rioja, págs. 49-58.

HARRIS, M. (2007): Introducción a la antropología general, Alianza Editorial, Madrid.

HARWICK, M. Jeffrey (2004): Mall Maker: Victor Gruen, architect of an American dream, University of Pennsylvania Press, Philadelphia.

JAMESON, F. (1991): El posmodernismo o la lógica cultural del capitalismo avanzado, Ediciones Paidós Ibérica, Barcelona.

KOWINSKI, W. S. (1985): The malling of America: an inside look at the great consumer paradise, William Morrow \& Co., New York.

Miller, M. B. (1981): The Bon Marche: Bourgeois Culture and the Department Store, 1869-1920, Princeton University Press, New Jersey.

Morales, M. C. (1981): Oviedo: Arquitectura y desarrollo urbano. Del Eclecticismo al Movimiento Moderno, Ethos Arte - Servicio de Publicaciones Universidad de Oviedo, Oviedo.

MORALES, M. C. (2009): "Los Calatrava de Oviedo", Liño, nº 15, Universidad de Oviedo, págs. 149-164.

Moro, M. (2007): Oviedo detrás de la fachada, Cambalache, Oviedo.

NAVASCUÉS, P., QUESADA, M. J. (1992): El siglo XIX: bajo el signo del Romanticismo, Sílex, Madrid.

PÉREZ, J. A. (1977): El barrio de Uría. De arrabal de enlace a centro comercial de Oviedo, Publicaciones del Colegio Oficial de Arquitectos de León y Asturias, Oviedo.

PevSNER, N. (1979): Historia de las tipologías arquitectónicas, Gustavo Gili, Barcelona.

RITZER, G. (2005): Enchanting a disenchanted world: revolutionizing the means of consumption, Pine Forge Press, California.

RodríGUEZ-VIGIL, J. M. (2011): Centros comerciales de la ciudad de Oviedo: arquitectura y urbanismo, Tesina de Licenciatura inédita, Universidad de Oviedo: Facultad de Filosofía y Letras.

TOBOsO, P. (2002): "Grandes almacenes y almacenes populares en España. Una visión histórica", Documentos de trabajo. Historia Económica (Fundación SEPI), n ${ }^{\mathrm{o}}$ 2, Fundación SEPI, págs. 1-140.

TOMÉ, S. (1988): Oviedo. La formación de la ciudad burguesa, 1850-1950, Colegio Oficial de Arquitectos de Asturias, Oviedo. 